\title{
Weather indices of agricultural production in the Netherlands 1948-1989. 2. Grassland
}

\author{
A. J. OSKAM ${ }^{1}$ \& A. J. REINHARD ${ }^{2}$ \\ ${ }^{1}$ Department of Agricultural Economics, Wageningen Agricultural University, P.O. Box \\ 8130, NL 6700 EW Wageningen, Netherlands \\ ${ }^{2}$ DLO-Agricultural Economics Research Institute, P.O. Box 29703, NL 2502 LS The \\ Hague, Netherlands
}

Received 9 September 1991; accepted 31 March 1992

\begin{abstract}
This paper elaborates three methods of deriving weather indices for grassland production. The methods are applied over the period 1948-1964, during which suitable data is available. Two methods are also useful to calculate weather indices outside this period. Examination of these methods shows that results of the applied methods differ considerably. Most extreme variations in yield are less than $20 \%$. The meteorological model is most suitable for calculating a weather index for a long period.
\end{abstract}

Keywords : weather indices, grassland, meteorological model

\section{Introduction}

Production and supply in the agricultural sector are not only determined by prices of outputs and inputs, quantities of quasi-fixed inputs, and technology but also by weather conditions which can have a strong influence on production and/or supply. Oskam (1991) indicates the usefulness of an indicator of weather conditions in many different areas of research. Here we will direct our attention to a weather index for grassland production. Various definitions of a weather index similar to those of the arable sector might be relevant, but we shall focus our attention on a definition derived from actual and normalized net production of grass, silage and hay.

The difficulty of measuring yields of grassland might be one of the reasons why literature on weather indices for grassland is scarce. Grass is grazed or harvested several times a year; the amount of grass grown differs from net production due to losses which also depend on weather. An ideal data set would contain experimental data on net production, with everything except weather, kept constant (Stallings, 1960), although systematic changes in the production technology on grassland could best be incorporated. The particular technology might be otherwise irrelevant when long-term developments are studied. But systematic data on 
net production of grassland is not available. Data from a group of experimental farms during the period 1948-1964 are available, however. These farms were used to demonstrate the effects of nitrogen fertilizer.

Starting with this data set we have used three different methods to estimate systematic yields and weather indices for grassland. The methods are:

1. Estimations of normalized yields of grassland during the period that data was available from variety trials and experimental fields, enabled us to derive the weather index from the relation between actual and normalized yields. This basic methodology has been applied already to the arable sector (Oskam, 1991). We call this the 'trend model'.

2. Yield data over the period 1948-1964 could be used to generate a meteorological model. This model relates the net production measure to characteristic variables for weather conditions. The estimated relation can be used for the prediction of the weather's effects on yields in other years. Normal yields can be derived from average weather conditions. We call this a 'meteorological model'.

3. Instead of weather variables, one might also relate net production data of grassland to weather indices of arable crops. Such weather indices are assumed to reflect also the weather conditions for grassland. The estimated relation can be used to generate indices outside the observation period. We call this the 'agronomic model'.

Because different approaches have been used to derive a set of weather indices for grassland production, the section methodology of this paper is extensive. Each method will be explained before its application. After the empirical results have been discussed, regional and national weather indices will be given.

\section{Methodology of constructing weather indices for grassland}

\section{Trend model}

This model assumes that systematic factors, fertilizer and weather determine the level of production. The model is similar to the model used for arable products (Oskam, 1991). Only a variable for the use of nitrogen fertilizer has been added:

$$
Y=\mathrm{f}(W, N, x)
$$

where: $Y=$ net yield of grassland; $W=$ weather conditions; $N=$ use of nitrogen fertilizer; $x=$ vector of other variables influencing net grass production.

Also here we used a polynomial trend function for the other variables. The variable $W$ consists of the disturbance term of either:

$$
\ln Y=\alpha_{0}+\alpha_{1} T+\alpha_{2} T^{2}+\alpha_{3} T^{3}+\alpha_{4} \ln N+\mu
$$

or: 


$$
Y=\beta_{0}+\beta_{1} T+\beta_{2} T^{2}+\beta_{3} T^{3}+\beta_{4} N+\tau
$$

where $\alpha$ 's and $\beta$ 's are parameters and $\mu$ and $\tau$ are disturbances. Two different types of specifications have been used, the log-linear and the linear. Because data of five different regions is available, we used an estimation procedure that incorporates the effects of correlated errors (e.g. correlated weather conditions) among the different regions. Known as Seemingly Unrelated Regression (SUR) in the literature (Judge et al. 1982: 321-325), this procedure uses the estimated errors of the Ordinary Least Squares (OLS) to generate an estimated variance-covariance matrix of the disturbances. This estimated variance-covariance matrix is used in a Generalized Least Squares (GLS) procedure. This estimation is more efficient than OLS. System estimation allows using restrictions among coefficients in different regions. Here, the coefficient of nitrogen will be restricted to similar types of soil.

As indicated by Oskam (1991) weather indices are derived from actual values of $\mathrm{Y}$ relative to estimated values.

\section{Meteorological model}

In a meteorological model the yield of grass in succeeding years will be related to input factors and to weather conditions. The production of grass at a specific soil type (in a certain region) can be described generally as:

$$
Y=\mathbf{f}(W e, F e, G m)
$$

where: $Y=$ net yield of grassland; We = weather (temperature, sunshine, precipitation, etc.); $F e=$ fertilizer (nitrogen fertilizer, manure); $G m=$ grassland management (grazing system, technology, grasstype).

Weather, fertilizer and grassland management can be represented by the following functions:

$$
\begin{aligned}
& W e=g\left(W e_{1}, . ., W e_{m}\right) \\
& F e=h\left(F e_{1}, \ldots, F e_{n}\right) \\
& G m=j\left(G m_{1}, \ldots, G m_{p}\right)
\end{aligned}
$$

First of all we assume that (4) is separable into its three basic variables (for a detailed explanation on separability: see Chambers, 1988: 110-115). This implies that, for example, the effect of nitrogen on the net yield of grassland $(Y)$ relative to the effect of grassland management on $Y$ will not be influenced by weather conditions.

Nitrogen, by far the most important fertilizer in the grassland sector, is used to reflect the amount of fertilizer applied. We also assume that grassland management can be represented by a time trend variable; this implies a continuous 
change of grassland management (technical changes included) in equal steps.

Weather in the Netherlands shows a certain regularity. A limited number of variables characterize weather conditions. The most important meteorological variables which influence grassland production are precipitation, evaporation, temperature and solar radiation (Deinum, 1966; Pellentier, 1984). The marginal returns of grassland production to weather variables are declining with higher values of these weather variables in alle time periods (Doll, 1967; Shaw, 1964; Thompson, 1969). Too much rain, for instance, will cause yield losses in harvesting grass, tracks of tractors and damage by cows. Therefore, quadratic functions are used for the specification of meteorological variables to allow for diminishing returns of precipitation, and so on.

The moisture available for the plant is taken into account by the evapotranspiration surplus, the difference between potential evapotranspiration and precipitation in the growing season; Equation 8. This is also a measure of damage caused by a surplus of water. The potential evapotranspiration is equal to the open water evaporation (calculated with the Penman formula) multiplied with a coefficient for grass $(0.8)$.

$$
R=E_{\mathrm{p}}-P
$$

where: $R=$ evapotranspiration surplus $(\mathrm{mm}) ; E_{\mathrm{p}}=$ potential evapotranspiration of grass $(\mathrm{mm}) ; P=$ precipitation $(\mathrm{mm})$.

Whether this precipitation and evaporation occur in April or in September does not make any difference for the model. The temperature is taken into account as the sum of the mean month temperature, and sunshine as the sum of hours of sunshine in the growing season (global radiation data is not available for the entire estimation period).

Besides meteorological variables which affect grass yield during the growing season, also the condition of the grassland at the beginning of the growing season will determine yield levels. A starting condition is, therefore, introduced in this model. This starting condition includes two related effects of winter temperature: a cold winter will delay the growing season of grass (Lemaire et al., 1983) and a part of the grass can be frozen to death during a cold winter (Larsen \& Arsvoll, 1984). This starting condition is determined by meteorological conditions in the preceding winter.

These variables enable us to reformulate (4) into the following form.

$$
Y=\mathrm{f}(S c, M, N, T)
$$

where: $S c=$ starting condition; $M=$ meteorological variables (evapotranspiration surplus, temperature, sunshine); $N=$ nitrogen fertilizer; $T=$ time trend variable.

Because the mean month temperature and the hours of sunshine are closely related to each other, they are never used together in one equation. Equation 9 can be specified in two alternative equations. Here we use the linear form, which facilitates incorporating the quadratic meteorological variables. 


$$
\begin{aligned}
& Y_{\mathrm{t}}=a_{0}+a_{1} T+a_{2} S c_{\mathrm{t}}+a_{3} N_{\mathrm{t}}+a_{4} S r_{\mathrm{t}}+a_{5} S r_{\mathrm{t}}^{2}+a_{6} S t_{\mathrm{t}}+a_{7} S t_{\mathrm{t}}^{2} \\
& Y_{\mathrm{t}}=b_{0}+b_{1} T+b_{2} S c_{\mathrm{t}}+b_{3} N_{\mathrm{t}}+b_{4} S r_{\mathrm{t}}+b_{5} S r_{\mathrm{t}}^{2}+b_{6} S h_{\mathrm{t}}+b_{7} S h^{2}{ }_{\mathrm{t}}
\end{aligned}
$$

where: $S r=$ evapotranspiration surplus in growing season; $S r^{2}=$ quadratic evapotranspiration surplus; $S t=$ sum of mean month temperature in growing season; $S t^{2}=$ quadratic sum of temperature; $S h=$ sum of hours of sunshine in growing season; $S h^{2}=$ quadratic sum of hours of sunshine; $a$ 's and $b$ 's are coefficients.

The plausibility of several coefficients of the meteorological model can be checked. Similar to the trend model, system estimation can be applied together by using restrictions on coefficients in different equations.

\section{Agronomic model}

The construction of a weather index for the arable sector is easier than for the grassland sector. Hence, a method is developed to use information on the effects of weather on arable crops to estimate the yield of grass.

The weather index of a combination of arable crops is meant to reflect the weather's influence on grassland. Oskam (1991) has calculated weather indices for twelve arable crops. A combination of the weather indices of winter wheat and sugar beets is used to simulate the weather conditions for grassland. Winter wheat, graminaceous like grass, starts growing in early spring. Sugar beets, like grass, have a growing season which lasts until November. A combination of both indices with the nitrogen application and a trend variable could simulate the production of grass of the respective years.

$$
Y=d_{0}+d_{1} T+d_{2} N+d_{3} W i_{\mathrm{ww}}+d_{4} W i_{\mathrm{sb}}
$$

where: $W i_{\mathrm{ww}}=$ weather index of winter wheat; $W i_{\mathrm{sb}}=$ weather index of sugar beets; $d$ 's are coefficients.

\section{Data}

Table 1 gives the data on yield and the use of nitrogen fertilizer of five different regions in the Netherlands. The data is based on the results of about 200 experimental farms. The main objective of the research on these farms was to measure the effects of nitrogen fertilizer on grassland production (Willemsen, 1966). Because the data plays a central role in our analysis, the data is again provided. The weather indices of winter wheat and sugar beets are provided by Oskam (1991).

\section{The weather variables}

Because the Netherlands is a small country with a sea-climate, meteorological changes during the growing season and among the different regions are small. The distribution of temperature, sunshine and evaporation of the Netherlands is al- 
Table 1. Net production of grassland in kilogram $(\mathrm{kg})$ starch value per ha and nitrogen fertilizer in $\mathrm{kg}$ $\mathrm{N}$ per hectare for five regions ${ }^{1}$ in the Netherlands.

\begin{tabular}{|c|c|c|c|c|c|c|c|c|c|c|}
\hline \multirow[t]{2}{*}{ Year } & \multicolumn{5}{|c|}{ Starch value } & \multicolumn{5}{|c|}{ Nitrogen } \\
\hline & Ns & $\mathrm{Cp}$ & $\mathrm{Cs}$ & Rcl & Ss & Ns & $\mathrm{Cp}$ & $\mathrm{Cs}$ & $\mathrm{Rcl}$ & Ss \\
\hline 1948 & 3170 & 3790 & 3450 & 3130 & 2760 & 66 & 66 & 77 & 67 & 68 \\
\hline 1949 & 3740 & 3720 & 3610 & 3120 & 3190 & 79 & 72 & 80 & 69 & 85 \\
\hline 1950 & 3710 & 3980 & 3670 & 3440 & 3410 & 103 & 86 & 100 & 77 & 97 \\
\hline 1951 & 3670 & 3920 & 3730 & 3760 & 3720 & 125 & 103 & 109 & 95 & 111 \\
\hline 1952 & 3920 & 4120 & 3740 & 3610 & 3550 & 143 & 105 & 114 & 106 & 117 \\
\hline 1953 & 4010 & 4110 & 4000 & 3910 & 3740 & 148 & 101 & 134 & 116 & 122 \\
\hline 1954 & 3450 & 3750 & 3450 & 3930 & 3610 & 151 & 125 & 131 & 126 & 143 \\
\hline 1955 & 3790 & 4120 & 3660 & 3770 & 3730 & 165 & 152 & 144 & 115 & 150 \\
\hline 1956 & 3420 & 3640 & 3330 & 3510 & 3590 & 163 & 126 & 135 & 119 & 156 \\
\hline 1957 & 3760 & 3880 & 3770 & 3620 & 4020 & 163 & 134 & 156 & 133 & 172 \\
\hline 1958 & 3700 & 3960 & 3720 & 3790 & 4090 & 164 & 128 & 140 & 149 & 174 \\
\hline 1959 & 3180 & 4050 & 3300 & 3400 & 3240 & 146 & 139 & 142 & 149 & 160 \\
\hline 1960 & 3760 & 4150 & 3780 & 4010 & 3950 & 170 & 126 & 152 & 167 & 184 \\
\hline 1961 & 3800 & 3940 & 4070 & 4230 & 4240 & 176 & 125 & 173 & 201 & 207 \\
\hline 1962 & 3650 & 3730 & 3900 & 3630 & 3860 & 205 & 172 & 219 & 192 & 230 \\
\hline 1963 & 3850 & 3580 & 3770 & 3870 & 3850 & 218 & 183 & 209 & 245 & 246 \\
\hline 1964 & 3970 & 3960 & 4350 & 3840 & 4220 & 220 & 176 & 220 & 221 & 239 \\
\hline
\end{tabular}

${ }^{1} \mathrm{Ns}=$ Northern sand area; $\mathrm{Cp}=$ Clay and peat area; $\mathrm{Cs}=$ Central sand area; Rcl = River clay and loess area; Ss = Southern sand area. Source: Wilemsen (1966).

most identical throughout the years. Precipitation shows more variation between regions. However, correlation analysis with precipitation data of the growing season of six meteorological stations across the country shows a high degree of correlation. To simplify the calculation of the weather index meteorological variables are all collected from the meteorological main station, located in the Bilt.

Because information on the relation between the meteorological conditions in the preceding winter and the condition of the grass sward is not available, a few possible relations between winter temperatures and the grass conditions in March at the beginning of the growing season have been tested. The consequences of a cold winter for grass differ according to soil types. Three types of starting conditions have been, therefore, considered for the different regions. The calculation of these three starting conditions is described in Appendix 1.

\section{Results of the empirical analysis}

\section{Trend model}

The results of the estimation procedure are stated in Table 2 . Here we provide the results of the log-linear model (Equation 2). We started with third degree orthogonal polynomials and dropped second and/or third degree elements when $t$-values in the OLS-functions were lower than 1.5. This method is based on the prediction 
Table 2. Estimation results for SUR-estimation of the log-linear trend model.

\begin{tabular}{lcllc}
\hline Area & \multicolumn{2}{c}{ Variables } & & \\
\cline { 2 - 5 } & Constant & $T$ & $T^{2}$ & $N$ \\
Northern Sand & & & & \\
& 6.11 & -0.020 & 0.0021 & 0.41 \\
Clay and Peat & $(0.20)^{1}$ & $(0.004)$ & $(0.0005)$ & $(0.04)$ \\
& 6.93 & -0.015 & - & 0.28 \\
Central Sand & $(0.27)$ & $(0.004)$ & & $(0.06)$ \\
River clay and Loess & 6.15 & -0.017 & 0.0018 & 0.41 \\
& $(0.20)$ & $(0.004)$ & $(0.0002)$ & $(0.04)$ \\
Southern Sand & 6.87 & -0.011 & -0.0008 & 0.28 \\
System weighted $R^{2}=0.855$ & $(0.27)$ & $(0.005)$ & $(0.0003)$ & $(0.06)$ \\
& 6.16 & -0.013 & - & 0.41 \\
& $(0.20)$ & $(0.004)$ & & $(0.04)$ \\
\hline
\end{tabular}

${ }^{1}$ Estimated standard errors within parentheses.

criterium described by Amemiya (1980 : 334). In a second round the equations were estimated by a SUR-method. Moreover, we restricted the coefficient for the effects of fertilizer on sandy soils to the same value. A similar restriction has been used for the Clay and Peat region and the River clay and Loess region.

The results of this estimation procedure seem plausible with a higher effect of fertilizer on sand and nearly equal constants among sandy soils and other soils. These constants reveal the 'natural' production without any nitrogen fertilizer. In a similar analysis using the linear model, one kilogram of nitrogen produced 9.4 and 7.7 kilograms of net starch value for sand and other soils, respectively. All regions show a negative log-linear trend in yields per hectare because the nitrogen effect has been separated. Such a development could be due to increased mechanization of grass production, harvesting, and such. This negative trend, however, is diminishing in the North and Central sand region.

The choice between the log-linear and the linear model is difficult because the estimation period is too short to justify testing the heteroscedasticity (see Oskam, 1991 and Judge et al., 1980 : Ch.4). Its theoretical plausibility enables us to use the results of the log-linear model. Differences with the linear model are always smaller than 0.015 for all the aggregated weather indices, with the exception of 1964 which showed a difference of 0.024 .

We used a similar method to that of Oskam (1991), to calculate the weather indices with an average value of 1.0 over the period 1948-1964 (see Table 3). Here average areas of grassland (including similar types of soils and regions) during the total period have been used to generate a weather index for total grassland in the Netherlands. Weights of regions are stated at the bottom of Table 3. The results of this period of seventeen years indicate that weather fluctuations explained $37 \%$ of the variation in yields, while the remaining percentage was attributed to systematic yield developments (including the effect of fertilizer). These results 
Table 3. Weather indices of grassland production of five different regions ${ }^{1}$ and the Netherlands (log-linear model).

\begin{tabular}{|c|c|c|c|c|c|c|c|c|c|c|c|c|}
\hline \multirow[t]{2}{*}{ Year } & \multicolumn{2}{|l|}{ Ns } & \multicolumn{2}{|l|}{$\mathrm{Cp}$} & \multicolumn{2}{|l|}{ Cs } & \multicolumn{2}{|l|}{$\mathrm{Rcl}$} & \multicolumn{2}{|l|}{ Ss } & \multicolumn{2}{|l|}{ Total } \\
\hline & 2 & 3 & 2 & 3 & 2 & 3 & 2 & 3 & 2 & 3 & 2 & 3 \\
\hline 1948 & 0.937 & 0.893 & 1.017 & 0.992 & 0.953 & 0.926 & 0.967 & 0.953 & 0.929 & 0.891 & 0.969 & 0.940 \\
\hline 1949 & 1.082 & 1.048 & 0.989 & 0.969 & 1.026 & 0.996 & 0.955 & 0.938 & 0.992 & 0.981 & 1.011 & 0.988 \\
\hline 1950 & 1.009 & 1.013 & 1.023 & 1.019 & 0.991 & 0.996 & 1.021 & 1.010 & 1.018 & 1.020 & 1.012 & 1.012 \\
\hline 1951 & 0.962 & 0.989 & 0.972 & 0.987 & 1.009 & 1.022 & 1.055 & 1.066 & 1.065 & 1.081 & 1.002 & 1.018 \\
\hline 1952 & 1.011 & 1.052 & 1.032 & 1.043 & 1.028 & 1.039 & 0.986 & 1.002 & 1.008 & 1.019 & 1.019 & 1.035 \\
\hline 1953 & 1.056 & 1.089 & 1.056 & 1.054 & 1.060 & 1.096 & 1.047 & 1.068 & 1.058 & 1.063 & 1.056 & 1.073 \\
\hline 1954 & 0.930 & 0.948 & 0.922 & 0.941 & 0.948 & 0.964 & 1.036 & 1.059 & 0.969 & 0.992 & 0.949 & 0.968 \\
\hline 1955 & 1.011 & 1.036 & 0.973 & 1.014 & 0.989 & 1.015 & 1.028 & 1.027 & 0.995 & 1.014 & 0.993 & 1.020 \\
\hline 1956 & 0.938 & 0.947 & 0.920 & 0.927 & 0.942 & 0.942 & 0.958 & 0.952 & 0.955 & 0.967 & 0.938 & 0.943 \\
\hline 1957 & 1.050 & 1.048 & 0.979 & 0.987 & 1.021 & 1.039 & 0.970 & 0.968 & 1.042 & 1.060 & 1.010 & 1.019 \\
\hline 1958 & 1.045 & 1.034 & 1.027 & 1.022 & 1.066 & 1.048 & 0.998 & 1.000 & 1.069 & 1.074 & 1.042 & 1.036 \\
\hline 1959 & 0.952 & 0.912 & 1.042 & 1.041 & 0.948 & 0.924 & 0.909 & 0.901 & 0.888 & 0.865 & 0.967 & 0.949 \\
\hline 1960 & 1.060 & 1.041 & 1.114 & 1.090 & 1.062 & 1.035 & 1.057 & 1.052 & 1.036 & 1.023 & 1.075 & 1.054 \\
\hline 1961 & 1.060 & 1.039 & 1.076 & 1.045 & 1.085 & 1.072 & 1.078 & 1.089 & 1.074 & 1.071 & 1.076 & 1.059 \\
\hline 1962 & 0.954 & 0.958 & 0.946 & 0.953 & 0.941 & 0.964 & 0.957 & 0.948 & 0.949 & 0.953 & 0.948 & 0.956 \\
\hline 1963 & 0.974 & 0.986 & 0.906 & 0.914 & 0.922 & 0.922 & 0.975 & 0.986 & 0.933 & 0.936 & 0.933 & 0.940 \\
\hline 1964 & 0.990 & 0.999 & 1.029 & 1.024 & 1.032 & 1.028 & 1.020 & 1.003 & 1.049 & 1.031 & 1.025 & 1.020 \\
\hline Weights & \multicolumn{2}{|c|}{0.174} & \multicolumn{2}{|c|}{0.332} & \multicolumn{2}{|c|}{0.232} & \multicolumn{2}{|c|}{0.110} & \multicolumn{2}{|c|}{0.152} & \multicolumn{2}{|c|}{1.000} \\
\hline
\end{tabular}

${ }^{1}$ See Table $1.2=$ with $\mathrm{N}$-variable included, $3=$ weighed trend models.

might not be representative for grassland in the Netherlands due to a different development of nitrogen application on the farms used in this analysis.

In this methodology all variations in the quantity of fertilizer have been considered as a systematic factor. Another approach would be to consider deviations from trends in the use of nitrogen due to weather conditions. If unfavourable weather conditions for grass production dictate that less nitrogen might be 'optimum', the quantity is accordingly reduced. These varying amounts lead to incorporating normalized values of the $\mathrm{N}$ variable in the Equations 2 and 3. Such an approach gives slightly different weather indices, while weather fluctuations explain a larger share of the total variation in net production: about $69 \%$. Table 3 gives the weather indices based on a weighed average of both methods.

\section{Meteorological model}

Since soil type and meteorological conditions differ from different regions, the relation between meteorological variables and yield is estimated for the distinguished regions.

We began by determining whether Equation 10 or 11 had the highest coefficient of multiple determination and gave coefficients with appropriate signs. For all regions the temperature variables (Equation 10) gave better results than that of 
Table 4. Estimation results for SUR-estimation of the meteorological model.

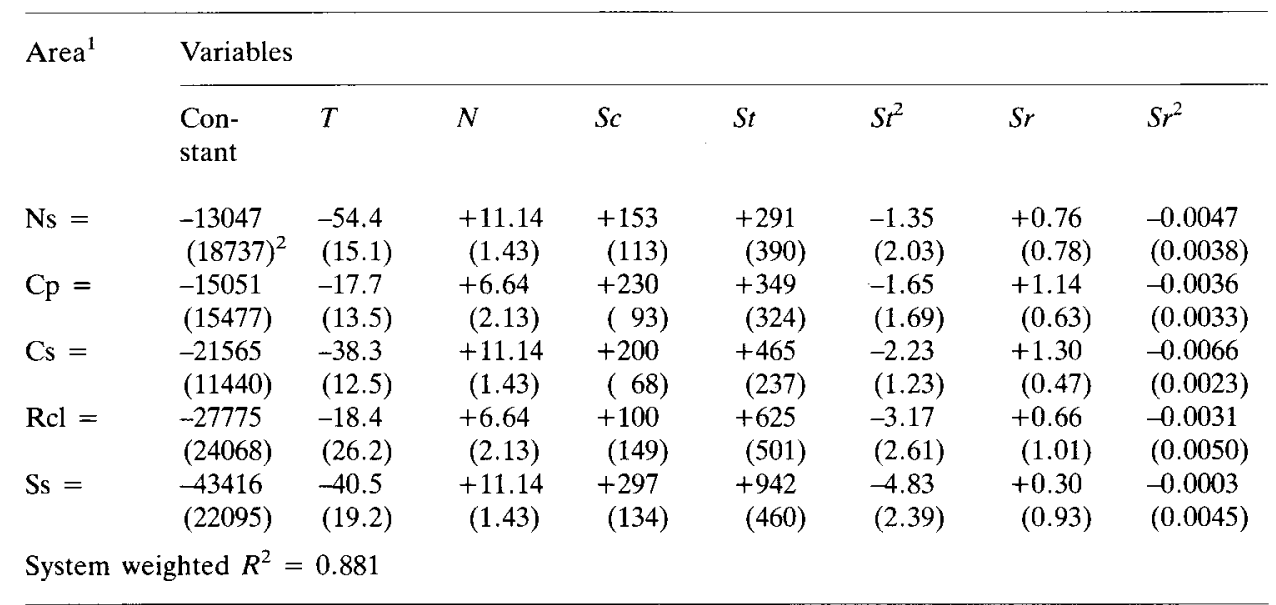

${ }^{1}$ See Table 1. ${ }^{2}$ Estimated standard errors within parentheses.

sunshine (Equation 11), probably due to the inadequacy of the sum of hours of sunshine as a sufficient estimator of solar radiation in the Netherlands.

Then three different variables for the starting condition were tested (see Appendix 1). The third starting condition resulted in the highest determination coefficient, and all coefficients had appropriate signs. The equations for the five regions were estimated with the SUR-method and the coefficients for the effects of fertilizer were restricted, as in the trend model. Estimation results are given in Table 4. According to the meteorological model one kilogram of nitrogen fertilizer produced 11.1 and 6.6 kilogram of net starch value for sand and other soils, respectively. Signs of the coefficients of the meteorological variables coincide with the theoretical requirements. Although all coefficients show the correct sign, they are not very reliable. All regions show a negative linear trend in yields per hectare.

The estimated equations have been used to compute the weather's influence on the yield of grass. Grassland management and the amount of fertilizer must remain constant. Hence, the average value of the trend factor and nitrogen application in the estimation period have been used. Calculated yields based on observed values of the weather variables have been divided by the average yield in the estimation period. This produces weather indices with an average value of 1.0 over the period 1948-1964; see Table 5. The same weights as those stated in Table 3 were used to compute a weather index for total grassland in the Netherlands. In the meteorological model weather variables explain $89 \%$ of the total variance in yields during the period 1948-1964.

\section{Agronomic model}

The parameters of Equation 12 are estimated for the five regions. In this regres- 


\section{A. J. OSKAM AND A. J. REINHARD}

Table 5. Weather indices of grassland production of five different regions ${ }^{1}$ and the Netherlands (meteorological model).

\begin{tabular}{lllllll}
\hline Year & Ns & Cp & Cs & Rcl & Ss & Total \\
1948 & 1.058 & 1.056 & 1.071 & 1.029 & 1.034 & 1.054 \\
1949 & 1.050 & 1.072 & 1.064 & 1.017 & 1.025 & 1.053 \\
1950 & 1.037 & 1.029 & 1.038 & 1.016 & 1.032 & 1.031 \\
1951 & 1.015 & 1.020 & 1.031 & 1.032 & 1.050 & 1.028 \\
1952 & 1.036 & 1.045 & 1.055 & 1.040 & 1.052 & 1.046 \\
1953 & 1.048 & 1.042 & 1.058 & 1.022 & 1.005 & 1.039 \\
1954 & 0.992 & 0.980 & 0.994 & 1.012 & 1.005 & 0.993 \\
1955 & 0.986 & 1.000 & 0.999 & 1.017 & 1.018 & 1.002 \\
1956 & 0.916 & 0.895 & 0.902 & 0.959 & 0.913 & 0.910 \\
1957 & 0.997 & 0.990 & 0.987 & 1.004 & 1.044 & 1.000 \\
1958 & 1.001 & 1.001 & 1.010 & 1.021 & 1.043 & 1.012 \\
1959 & 0.958 & 1.009 & 1.928 & 0.898 & 0.894 & 0.952 \\
1960 & 1.038 & 1.038 & 1.053 & 1.039 & 1.050 & 1.043 \\
1961 & 1.054 & 1.047 & 1.059 & 1.017 & 1.019 & 1.043 \\
1962 & 0.911 & 0.912 & 0.897 & 0.928 & 0.917 & 0.911 \\
1963 & 0.909 & 0.875 & 0.883 & 0.957 & 0.903 & 0.896 \\
1964 & 0.988 & 0.990 & 0.998 & 1.014 & 1.015 & 0.998 \\
Weights & 0.174 & 0.332 & 0.232 & 0.110 & 0.152 & 1.000 \\
\hline
\end{tabular}

${ }^{1}$ See Table 1.

sion analysis the coefficient of the weather index of winter wheat which had a negative sign in two regions is not consistent with the theory. The weather index of winter wheat has been, thus, omitted. The equations for the five regions are estimated with the SUR-method and the coefficients for the effects of fertilizer are

Table 6. Estimation results for SUR estimation of the agronomic model.

\begin{tabular}{|c|c|c|c|c|}
\hline \multirow[t]{2}{*}{ Area } & \multicolumn{4}{|c|}{ Variables } \\
\hline & Const & $T$ & $N$ & $W i_{s b}$ \\
\hline Northern Sand & $\begin{array}{l}1414 \\
(398)^{1}\end{array}$ & $\begin{array}{l}-71.7 \\
(14.1)\end{array}$ & $\begin{array}{r}+10.05 \\
(1.49)\end{array}$ & $\begin{array}{r}+1359 \\
(372)\end{array}$ \\
\hline Clay and Peat & $\begin{array}{l}2400 \\
(460)\end{array}$ & $\begin{array}{l}-38.0 \\
(14.2)\end{array}$ & $+\begin{array}{c}5.25 \\
(1.83)\end{array}$ & $\begin{array}{r}+1184 \\
(414)\end{array}$ \\
\hline Central Sand & $\begin{array}{l}1239 \\
(351)\end{array}$ & $\begin{array}{l}-61.6 \\
(13.9)\end{array}$ & $\begin{array}{r}+10.05 \\
(1.49)\end{array}$ & $\begin{array}{r}+1587 \\
(329)\end{array}$ \\
\hline River clay and Loess & $\begin{array}{l}2719 \\
(600)\end{array}$ & $\begin{array}{l}-19.6 \\
(22.1)\end{array}$ & $\begin{array}{c}5.25 \\
(1.83)\end{array}$ & $\begin{array}{c}+409 \\
(598)\end{array}$ \\
\hline Southern Sand & $\begin{array}{l}1567 \\
(600)\end{array}$ & $\begin{array}{l}-51.6 \\
(19.9)\end{array}$ & $\begin{array}{c}+10.05 \\
(1.49)\end{array}$ & $\begin{array}{r}+1008 \\
(590)\end{array}$ \\
\hline
\end{tabular}

\footnotetext{
${ }^{1}$ Estimated standard errors within parentheses.
} 
Table 7. Weather indices of grassland production of five different regions ${ }^{1}$ and the Netherlands (agronomic model).

\begin{tabular}{lllllll}
\hline Year & Ns & Cp & Cs & Rcl & Ss & Total \\
1948 & 1.015 & 1.013 & 1.018 & 1.005 & 1.011 & 1.013 \\
1949 & 1.003 & 1.003 & 1.004 & 1.001 & 1.002 & 1.003 \\
1950 & 1.001 & 1.000 & 1.001 & 1.000 & 1.000 & 1.000 \\
1951 & 0.952 & 0.961 & 0.945 & 0.986 & 0.965 & 0.959 \\
1952 & 1.025 & 1.020 & 1.029 & 1.007 & 1.018 & 1.021 \\
1953 & 1.018 & 1.015 & 1.021 & 1.005 & 1.014 & 1.016 \\
1954 & 0.954 & 0.963 & 0.947 & 0.986 & 0.966 & 0.961 \\
1955 & 1.010 & 1.008 & 1.012 & 1.003 & 1.007 & 1.009 \\
1956 & 0.942 & 0.952 & 0.933 & 0.982 & 0.957 & 0.950 \\
1957 & 0.991 & 0.993 & 0.990 & 0.997 & 0.994 & 0.993 \\
1958 & 1.043 & 1.035 & 1.049 & 1.013 & 1.032 & 1.037 \\
1959 & 0.945 & 0.955 & 0.936 & 0.983 & 0.959 & 0.952 \\
1960 & 1.061 & 1.050 & 1.070 & 1.018 & 1.045 & 1.052 \\
1961 & 1.019 & 1.016 & 1.022 & 1.006 & 1.014 & 1.017 \\
1962 & 0.970 & 0.976 & 0.966 & 0.991 & 0.978 & 0.974 \\
1963 & 0.980 & 0.983 & 0.977 & 0.994 & 0.985 & 0.983 \\
1964 & 1.071 & 1.058 & 1.082 & 1.021 & 1.052 & 1.061 \\
Weights & 0.174 & 0.332 & 0.232 & 0.110 & 0.152 & 1.000 \\
\hline
\end{tabular}

${ }^{1}$ See Table 1.

restricted as those in the trend model. The estimated parameters are given in Table 6. According to the agronomic model one kilogram of nitrogen produced 10.1 and 5.3 kilogram of net starch value for sand and other soils, respectively. All regions show a negative linear trend in yields per hectare.

The estimated equations are used to compute the weather's influence on the yield of grass. The value of the trend factor and nitrogen application used for this calculation is the average value of these variables in the estimation period. The calculated grass yields are divided by the average yield in the estimation period. This produces weather indices with an average value of 1.0 over the period 1948-1964 which are given in Table 7. Here again, the weights presented in Table 3 are used to compute a weather index for total grassland production in the Netherlands. In the agronomic model weather variables explain $33 \%$ of the total variance in yields during the period 1948-1964.

\section{Discussion}

\section{Different models}

Various methods have been used to generate weather indices for grassland production in the Netherlands. The results of all methods can be compared for the period 1948-1964. It is important to observe the difference in starting points of the trend model on the one hand and that of the meteorological model and the 
agronomic model on the other hand. The trend model tries to explain systematic yields. Here the weather index is a 'by-product' of the method. All other disturbances which are not due to weather are included in the weather index. Therefore, one might expect that the trend model would give a higher standard deviation of the weather indices: see also Oskam (1991) for an elaborate discussion of the trend model.

The meteorological model explains the differences in yield by deviations of meteorological variables when trend and nitrogen application are kept constant. All other disturbances unrelated to weather are excluded in this weather index. We expect a lower standard deviation of these weather indices than from the trend model.

In the agronomic model the weather index of sugar beets is used and is meant to include the effects of weather on grassland. When the similarity between the influence of the weather on sugar beets and on grassland is perfect, the variance would approximately have the same value as the variance of the trend model. The agronomic model underestimates the effects weather will have on grassland production because the weather index of sugar beets is assumed to be an imperfect indicator of weather conditions for grassland. We expect a smaller variance than that which was calculated with the trend model. Contrary to our expectations the weather index computed by the meteorological model has the largest variance and also the largest difference between the extremes, about $16 \%$ between the years 1963 and 1948 (Table 8). Weather variance within the agronomic model is smaller than in the trend model, this is according to our expectations.

\section{The trend model}

A period of seventeen years is short for a reliable polynomial trend model. Systematic differences in weather between the first and last part of the period 1948-1964 are incorporated in the trend coefficient. Weather effects could be incorporated partly as systematic effects. We illustrate this phenomenon by comparing the trend model and the meteorological model. The weather indices cal-

Table 8. Standard deviations of weather indices calculated by the trend, meteorological and the agronomic model per region (1948-1964).

Area

Northern Sand

Clay and Peat

Central Sand

River clay and Loess

Southern Sand

Total weather index
Standard deviations

\begin{tabular}{lll}
\hline Trend & Meteo. & Agron. \\
0.0546 & 0.0505 & 0.0390 \\
0.0488 & 0.0572 & 0.0320 \\
0.0535 & 0.0631 & 0.0450 \\
0.0535 & 0.0404 & 0.0117 \\
0.0637 & 0.0562 & 0.0289 \\
0.0447 & 0.0526 & 0.0336 \\
\hline
\end{tabular}


culated with the meteorological model contain a significant trend of -0.006 in the estimation period, expressing systematic differences in weather conditions between the first and second part of the estimation period. In a longer period the weather index calculated with the meteorological model does not contain any trend. Due to the estimation method, the weather indices computed with the trend model do not show any trend. In calculating the final weather index of grassland, we used the observed trends in the meteorological model to correct the results for the trend model.

\section{The meteorological model}

The meteorological model is the most elaborate model of the three models. Several variables are included to construct a model that reflects the actual yield level of grassland under different weather conditions. Different equations are used for the different regions. In Table 9 the correlation between the total weather index and the indices of the regions are given for the meteorological model. The correlation is high; the regional approach for the meteorological model did not yield significantly better weather indices.

This meteorological model which is still a simplification includes only the main meteorological influences on the grass yield. Although grass is less vulnerable than other crops, sporadic climatic conditions such as hail storms, early or late frosts can often have devastating effects on crops. This meteorological model does not incorporate these events. The real influence of meteorological variables could be misrepresented by using sums of the meteorological data during the entire growing season. Averaging temperature data for a period of one month already gives deviations while two weeks of very warm weather offset by two weeks of very cool weather may average out near to normal. Adding these mean month temperatures leads to more disturbances. The evapotranspiration data contain equal shortcomings. Because of the reigning sea climate in the Netherlands, this summation will only cause minor deviations as compared with other countries. This functional relation between net yield and meteorological variables is only valid for certain intervals of meteorological variables relevant to circumstances in the Netherlands.

Table 9. Correlation between the total weather index of grassland and the weather index of five regions for the trend model and the meteorological model (period 1948-1964).

Area

Northern Sand

Clay and Peat

Central Sand

Riverclay and Loess

Southern Sand
Correlation

\begin{tabular}{ll}
\hline trend & meteorological \\
0.85 & 0.99 \\
0.76 & 0.95 \\
0.97 & 0.99 \\
0.71 & 0.84 \\
0.85 & 0.89
\end{tabular}


For other countries other simplifications have been used. Indeed, some of the most effective statistical meteorological models have been developed in areas where variation in crop growth and yield are governed by a single, major weather factor (see, for instance Doll (1967) and Parry et al. (1988: 420)). Most researchers, assuming a strong relation between temperature and yield, use temperature as the single meteorological variable in their model.

\section{The agronomic model}

The agronomic model assumes similar relations with meteorological circumstances between arable products and grassland. The growing season of winter wheat and sugar beets coincides with that of grass. The empirical results only show a relation between sugar beets and grass. Theoretically, information about meteorological conditions in early spring is lacking. The correlation between the regions is perfect, because the value of the weather index depends entirely on the value of the weather index of sugar beets. So there is linear dependency.

\section{Conclusions of the analysis for grassland}

All models produced negative trends and coefficients for the nitrogen application which vary between 11.1 and 5.3 kilogram of net starch value per $\mathrm{kg}$ of nitrogen. In all models one kilogram of nitrogen produced more kilograms of net starch value on sandy soils than on other soils. The weather indices estimated by the three methods applied differed considerably as is shown in Table 10.

The meteorological and the agronomic model offer the possibility to calculate a weather index for grassland outside the estimation period. With both models weather indices for grassland are constructed for the period 1948-1989; these are given in Table 11. To compare the weather indices of the grassland sector and the arable sector, these weather indices have an average value of 1.0 during the period 1951-1985 (see Oskam, 1991). Therefore, these results differ with data provided in Table 5 and 7 . The strikingly small value of the weather index of the meteo-

Table 10. Correlation between weather indices calculated by the trend model, the meteorological model and the agronomic model per region (1948-1964).

\begin{tabular}{llll}
\hline Area & \multicolumn{2}{l}{ Correlation } & \\
\cline { 2 - 4 } & trend-meteo. & trend-agron. & meteo.-agron. \\
& & & \\
Northern Sand & 0.43 & 0.54 & 0.52 \\
Clay and Peat & 0.71 & 0.64 & 0.46 \\
Central Sand & 0.61 & 0.59 & 0.57 \\
Riverclay and Loess & 0.64 & 0.31 & 0.61 \\
Southern Sand & 0.67 & 0.41 & 0.59 \\
Total weather index & 0.66 & 0.64 & 0.56 \\
\hline
\end{tabular}


Table 11. Weather indices of grassland production calculated by the agronomic model and the meteorological model of the Netherlands in the period 1948-1989, and the final weather index of five different regions ${ }^{1}$ and the Netherlands.

\begin{tabular}{|c|c|c|c|c|c|c|c|c|}
\hline \multirow[t]{2}{*}{ Year } & \multirow{2}{*}{$\begin{array}{l}\text { Agron. } \\
\text { model } \\
\text { Total }\end{array}$} & \multirow{2}{*}{$\begin{array}{l}\text { Meteor. } \\
\text { model } \\
\text { Total }\end{array}$} & \multicolumn{6}{|c|}{ Final weather index of grassland } \\
\hline & & & Ns & $\mathrm{Cp}$ & $\mathrm{Cs}$ & $\mathrm{Rcl}$ & Ss & Total \\
\hline 1948 & 1.016 & 1.053 & 0.950 & 0.993 & 0.964 & 0.969 & 0.932 & 0.967 \\
\hline 1949 & 1.005 & 1.052 & 1.022 & 0.993 & 0.996 & 0.957 & 0.973 & 0.992 \\
\hline 1950 & 1.003 & 1.030 & 1.002 & 0.998 & 0.987 & 0.994 & 0.997 & 0.996 \\
\hline 1951 & 0.961 & 1.027 & 0.982 & 0.981 & 0.999 & 1.030 & 1.038 & 1.000 \\
\hline 1952 & 1.024 & 1.045 & 1.026 & 1.024 & 1.023 & 1.005 & 1.012 & 1.020 \\
\hline 1953 & 1.018 & 1.038 & 1.053 & 1.031 & 1.056 & 1.030 & 1.013 & 1.038 \\
\hline 1954 & 0.963 & 0.992 & 0.959 & 0.948 & 0.964 & 1.023 & 0.981 & 0.967 \\
\hline 1955 & 1.011 & 1.001 & 1.002 & 0.997 & 0.994 & 1.012 & 1.000 & 0.999 \\
\hline 1956 & 0.962 & 0.909 & 0.926 & 0.905 & 0.914 & 0.948 & 0.928 & 0.919 \\
\hline 1957 & 0.995 & 0.999 & 1.020 & 0.985 & 1.008 & 0.980 & 1.041 & 1.004 \\
\hline 1958 & 1.039 & 1.011 & 1.018 & 1.011 & 1.028 & 1.006 & 1.050 & 1.022 \\
\hline 1959 & 0.955 & 0.951 & 0.938 & 1.028 & 0.927 & 0.898 & 0.875 & 0.951 \\
\hline 1960 & 1.055 & 1.042 & 1.046 & 1.071 & 1.050 & 1.044 & 1.034 & 1.053 \\
\hline 1961 & 1.019 & 1.043 & 1.056 & 1.056 & 1.076 & 1.054 & 1.045 & 1.059 \\
\hline 1962 & 0.977 & 0.910 & 0.946 & 0.945 & 0.943 & 0.941 & 0.938 & 0.943 \\
\hline 1963 & 0.985 & 0.895 & 0.963 & 0.909 & 0.918 & 0.977 & 0.925 & 0.930 \\
\hline 1964 & 1.063 & 0.997 & 1.011 & 1.027 & 1.034 & 1.016 & 1.032 & 1.026 \\
\hline 1965 & 0.988 & 0.823 & 0.894 & 0.892 & 0.855 & 0.928 & 0.954 & 0.897 \\
\hline 1966 & 0.977 & 0.977 & 0.973 & 0.962 & 0.948 & 0.978 & 1.015 & 0.970 \\
\hline 1967 & 1.041 & 1.060 & 1.056 & 1.060 & 1.069 & 1.025 & 1.023 & 1.052 \\
\hline 1968 & 1.016 & 0.976 & 0.978 & 0.962 & 0.954 & 0.976 & 0.992 & 0.969 \\
\hline 1969 & 1.033 & 1.022 & 1.040 & 1.024 & 1.036 & 0.989 & 0.952 & 1.015 \\
\hline 1970 & 1.004 & 1.001 & 0.995 & 0.986 & 1.000 & 1.011 & 0.990 & 0.994 \\
\hline 1971 & 1.046 & 1.034 & 1.007 & 1.030 & 1.023 & 1.025 & 1.048 & 1.026 \\
\hline 1972 & 0.994 & 0.989 & 0.974 & 0.974 & 0.976 & 0.996 & 1.006 & 0.982 \\
\hline 1973 & 0.997 & 1.041 & 1.027 & 1.029 & 1.040 & 1.030 & 1.040 & 1.033 \\
\hline 1974 & 0.980 & 0.990 & 0.975 & 0.975 & 0.976 & 0.996 & 1.013 & 0.983 \\
\hline 1975 & 0.969 & 1.052 & 1.030 & 1.054 & 1.046 & 1.028 & 1.048 & 1.044 \\
\hline 1976 & 0.983 & 1.014 & 0.991 & 1.043 & 0.986 & 0.971 & 1.004 & 1.007 \\
\hline 1977 & 0.988 & 1.052 & 1.036 & 1.045 & 1.053 & 1.035 & 1.049 & 1.045 \\
\hline 1978 & 1.001 & 1.023 & 1.004 & 1.014 & 1.018 & 1.022 & 1.029 & 1.016 \\
\hline 1979 & 0.977 & 0.955 & 0.954 & 0.934 & 0.947 & 0.986 & 0.945 & 0.948 \\
\hline 1980 & 0.993 & 1.038 & 1.025 & 1.024 & 1.035 & 1.028 & 1.044 & 1.030 \\
\hline 1981 & 1.018 & 1.039 & 1.036 & 1.032 & 1.045 & 1.022 & 1.014 & 1.032 \\
\hline 1982 & 1.048 & 1.021 & 1.026 & 1.041 & 1.025 & 0.977 & 0.948 & 1.013 \\
\hline 1983 & 0.961 & 1.042 & 1.054 & 1.045 & 1.055 & 1.000 & 0.982 & 1.034 \\
\hline 1984 & 0.993 & 1.014 & 1.000 & 0.998 & 1.007 & 1.016 & 1.027 & 1.007 \\
\hline 1985 & 0.975 & 0.977 & 0.978 & 0.958 & 0.973 & 0.997 & 0.963 & 0.970 \\
\hline 1986 & 1.034 & 0.989 & 0.975 & 0.980 & 0.981 & 1.004 & 0.983 & 0.982 \\
\hline 1987 & 0.991 & 0.979 & 0.973 & 0.959 & 0.967 & 0.996 & 0.989 & 0.972 \\
\hline 1988 & 1.002 & 1.058 & 1.043 & 1.059 & 1.060 & 1.030 & 1.041 & 1.050 \\
\hline 1989 & 1.023 & 0.991 & 1.002 & 1.043 & 0.980 & 0.910 & 0.896 & 0.984 \\
\hline mean & 1.002 & 1.004 & 0.999 & 1.000 & 0.999 & 0.997 & 0.996 & 0.999 \\
\hline st.dev. & 0.028 & 0.050 & 0.039 & 0.045 & 0.048 & 0.035 & 0.045 & 0.039 \\
\hline
\end{tabular}

${ }^{1}$ See Table 1. 
rological model in 1965 is caused by excessive precipitation which we did not assess in the estimation period when heavy precipitation did not occur. Thus, this excessive precipitation which has not been incorporated in the meteorological model will cause biases. In other data sources 1965 does not seem to be a year with extremely low grass yields. In dry years the difference between different regions is remarkable. The weather index of the meteorological model of the Clay and Peat region in the years 1959 and 1976 reflect a large production. This region is less vulnerable to drought than other regions due to a constant groundwater level and moisture-containing properties of the soil.

We will use two criteria to construct a resultant weather index:

1. A particular approach which gives results without major drawbacks will be incorporated.

2. The construction should be simple.

The corrected results of the trend model can only be incorporated over the period 1948-1964. The agronomic model underestimated the effect of weather conditions and does not contain any information about the early spring. We conclude that the meteorological model best fulfills the theoretical constraints outside the estimation period. We cannot prove whether the trend model or the meteorological model provides the best weather index in the estimation period. In the period 1948-1964 the average value of the corrected trend and the meteorological model has been used. From 1965 on, the meteorological model has been used. For the year 1965, specifically, the average value of the meteorological model and the agronomic model has been used due to the observed bias.

Although the calculated weather index has a number of drawbacks, it forms the only consistent long-term source in this area. This final weather index for grassland is presented in Table 11.

\section{Appendix 1}

\section{The calculation of the starting conditions}

The variable $S c$ is a proxy variable for the Starting condition. This variable is composed from the mean temperature of every winter month (a winter consists of December - February). To obtain negative values only, $10^{\circ} \mathrm{C}$ are subtracted from the mean month temperatures. Three different variables have been constructed. 1. To compute $S c_{1}$ these transformed temperatures for each winter are added, and this sum is multiplied 59 if December is the coldest month: by 74 if January is the coldest month or by 91 if February is the coldest winter month. The calculated values of the period 1948 - 1985 are scaled into a queue of values with an average value of 0 and a difference between the smallest and largest value of 2 .

2. $S c_{2}$ is created by giving all the values of $S c_{1}$ which are larger than 0.25 the value 0.25 . The philosophy behind this correction is that only very cold winters have any (negative) effect on the condition of the grass in March. If a winter does not have any cold periods, the actual value of the mean month temperature 
WEATHER INDICES FOR AGRICULTURAL PRODUCTION. 2

Table A1. The mean month temperatures in winter and the calculated starting conditions.

\begin{tabular}{|c|c|c|c|c|c|c|}
\hline \multirow[t]{2}{*}{ Year } & \multicolumn{3}{|c|}{ Mean month temperatures in ${ }^{\circ} \mathrm{C}$} & \multicolumn{3}{|c|}{ Starting conditions } \\
\hline & $\begin{array}{l}\text { December } \\
\text { year }_{t-1}\end{array}$ & $\begin{array}{l}\text { January } \\
\text { year, }_{t}\end{array}$ & $\begin{array}{l}\text { February } \\
\text { year, }\end{array}$ & $S c_{1}$ & $S c_{2}$ & $S c_{3}$ \\
\hline 1948 & 4.2 & 5.1 & 3.0 & 0.15 & 0.15 & 0.25 \\
\hline 1949 & 3.5 & 3.7 & 3.8 & 0.60 & 0.25 & 0.25 \\
\hline 1950 & 4.4 & 1.0 & 5.5 & 0.09 & 0.09 & 0.25 \\
\hline 1951 & -1.2 & 4.0 & 3.9 & 0.29 & 0.29 & 0.18 \\
\hline 1952 & 4.3 & 2.5 & 2.5 & 0.06 & 0.06 & 0.11 \\
\hline 1953 & 1.5 & 1.4 & 2.5 & 0.15 & 0.15 & -0.10 \\
\hline 1954 & 5.3 & 0.4 & -0.3 & -0.40 & -0.40 & -0.37 \\
\hline 1955 & 5.5 & 0.3 & 0.3 & -0.30 & -0.30 & -0.30 \\
\hline 1956 & 4.8 & 2.2 & -6.4 & -1.40 & -1.40 & -1.01 \\
\hline 1957 & 5.3 & 3.6 & 5.0 & 0.44 & 0.25 & 0.25 \\
\hline 1958 & 3.1 & 2.2 & 3.8 & 0.25 & 0.25 & 0.20 \\
\hline 1959 & 4.5 & 1.6 & 0.7 & -0.23 & -0.23 & -0.18 \\
\hline 1960 & 4.1 & 2.5 & 2.9 & 0.29 & 0.25 & 0.15 \\
\hline 1961 & 3.2 & 2.0 & 5.9 & 0.23 & 0.23 & 0.25 \\
\hline 1962 & 1.7 & 3.5 & 2.8 & 0.11 & 0.11 & 0.12 \\
\hline 1963 & -0.7 & -5.3 & -3.4 & -0.75 & -0.75 & -1.49 \\
\hline 1964 & -1.0 & 0.7 & 3.5 & 0.12 & 0.12 & -0.14 \\
\hline 1965 & 2.2 & 2.5 & 2.0 & -0.02 & -0.02 & -0.04 \\
\hline 1966 & 4.4 & 0.4 & 4.1 & 0.01 & 0.01 & 0.14 \\
\hline 1967 & 4.4 & 3.0 & 5.1 & 0.36 & 0.25 & 0.25 \\
\hline 1968 & 3.4 & 2.2 & 1.4 & -0.12 & -0.12 & -0.09 \\
\hline 1969 & 0.0 & 4.6 & 0.2 & -0.31 & 0.31 & -0.18 \\
\hline 1970 & -1.4 & 0.6 & 1.1 & 0.08 & 0.08 & -0.46 \\
\hline 1971 & 2.4 & 2.3 & 3.8 & 0.27 & 0.25 & 0.18 \\
\hline 1972 & 5.4 & 0.5 & 3.6 & 0.03 & 0.03 & 0.13 \\
\hline 1973 & 3.3 & 2.9 & 2.9 & 0.13 & 0.13 & 0.15 \\
\hline 1974 & 2.7 & 5.2 & 4.6 & 0.41 & 0.25 & 0.25 \\
\hline 1975 & 7.3 & 6.2 & 3.1 & 0.16 & 0.16 & 0.25 \\
\hline 1976 & 3.5 & 4.2 & 2.9 & 0.13 & 0.13 & 0.25 \\
\hline 1977 & 1.7 & 3.0 & 4.9 & 0.41 & 0.25 & 0.25 \\
\hline 1978 & 5.0 & 3.0 & 1.1 & -0.17 & -0.17 & 0.00 \\
\hline 1979 & 1.8 & -3.2 & -0.9 & -0.47 & -0.47 & -0.90 \\
\hline 1980 & 5.4 & 0.2 & 4.8 & -0.01 & -0.01 & 0.25 \\
\hline 1981 & 3.6 & 2.7 & 1.5 & -0.10 & -0.10 & -0.03 \\
\hline 1982 & -0.7 & 1.1 & 2.8 & 0.16 & 0.16 & -0.18 \\
\hline 1983 & 3.4 & 6.2 & 0.9 & -0.20 & -0.20 & 0.18 \\
\hline 1984 & 3.8 & 3.4 & 2.0 & -0.02 & -0.02 & 0.10 \\
\hline 1985 & 4.3 & -3.1 & -0.6 & -0.45 & -0.45 & -0.75 \\
\hline 1986 & 5.7 & 2.4 & -3.6 & -0.94 & -0.94 & -0.60 \\
\hline 1987 & 5.1 & -2.7 & 2.1 & -0.40 & -0.40 & -0.34 \\
\hline 1988 & 4.4 & 5.9 & 4.6 & 0.41 & 0.25 & 0.25 \\
\hline 1989 & 7.0 & 4.5 & 5.3 & 0.56 & 0.25 & 0.25 \\
\hline
\end{tabular}


does not have any bearing on the condition of the grass.

3. $S c_{3}$ is calculated out of the transformed mean month temperature as follows:

$$
3 * T(\text { February })+2 * T(\text { January })+1 * T(\text { December })
$$

where: $T=$ mean month temperature minus $10^{\circ} \mathrm{C}$.

The calculated values of $S c_{3}$ are standardized as given in 1 . All the standardized values larger than 0.25 are given in the value 0.25 as described in 2 .

These three different starting conditions refer to different ways grass can react upon winter conditions. The greatest differences between $S c_{2}$ and $S c_{3}$ are found in very cold winters. In cold winters with one very cold month (for instance, 1956) $S c_{2}$ will have a smaller value (a larger negative value) than $S c_{3}$. In winters with three cold months (for instance, 1963) $S c_{3}$ will show a smaller value than $S c_{2}$; see also Table A1.

It could be that the starting condition is of declining importance. Nowadays grassland is renewed by seeding grass on the old grass surface after a very cold winter. In this way a cold winter will not effect the starting condition and the grass yield as much as in the estimation period.

The mean month temperatures used for the calculation, and the computed starting conditions are given in Table A1.

\section{References}

Amemiya, T., 1980. Selection of regressors. International Economic Review 21: 321-354.

Chambers, R. G., 1988. Applied production analysis: A dual approach, Cambridge University Press, Cambridge, $331 \mathrm{pp}$.

Deinum, B., 1966. Climate, Nitrogen and Grass. H. Veenman \& Zn, Wageningen, 91 pp.

Doll, J. P., 1967. An analytical technique for estimating weather indices from meteorological measurements. Journal of farm Economics 49: 79-88.

Judge. G. C., W. E. Griffits, R. C. Hill \& T-C Lee, 1980. The theory and practice of econometrics, Wiley, New York, 810 pp.

Judge, G. C., R. C. Hill, W. E. Griffits, H. Lütkepohl \& T-C. Lee, 1982. Introduction to the theory and practice of econometrics. Wiley, New York, $839 \mathrm{pp}$.

Larsen, A. \& K. Arsvoll, 1984. The impact of biotic and physical overwintering factors on grassland production, and their relations to climate, soil properties and management. In: H. Riley \& A. O. Skjelvag (Eds), The impact of climate on grass production and quality. Proceedings of the 10th General Meeting of the European Grassland Federation, p. 534-538. The Norwegian State Agricultural Research Stations, As.

Lemaire, G., J. Salette, G. Gosse \& M. Chartier, 1983. Temperature and spring growth for grasses: comparison of different grass stands. In: Corrall, A.J. (Ed.), Efficient grassland farming. Proceedings of the 9th General Meeting of the European Grassland Federation, p 268-277. The British Grassland Society, Reading.

Oskam, A. J., 1991. Weather indices for agricultural production in the Netherlands 1948-1989. 1. Generel methodology and the arable sector. Netherlands Journal of Agricultural Science 39: 149-164.

Pellier, P., 1984. The effect of climate on grass production on grazed permanent pastures. Consequences for the fitted stocking rate. In: H. Riley \& A.O. Skjelvag (Eds), The impact of climate on grass production and quality. Proceedings of the 10th General Meeting of the European Grassland Federation, p. 534-538. The Norwegian State Agricultural Research Stations, As.

Parry, M. L., T. R. Carter \& N. T. Konijn (Eds), 1988. The Impact of Climatic Variations on 
Agriculture, Vol. 1: Assessment in cool temperate and cold regions. Kluwer Academic Publishers, Dordrecht, $876 \mathrm{pp}$.

Shaw, L. H., 1964. The efffect of weather on agricultural output: A look at methodology. Journal of Farm Economics 46: 218-230.

Stallings, J. L., 1960. Weather indices. Journal of Farm Economics 42: 180-186.

Thompson, L. M., 1969. Weather and technology in the production of corn in the U.S. Corn Belt. Agronomy Journal 61: 45-456.

Willemsen, W., 1966. Seventeen years net starch value yields of grassland on nitrogen pilot farms (In Dutch). Stikstof 47/48: 443-448. 